\title{
Depression and Social Defeat Stress Are Associated with Inhibitory Synaptic Changes in the Nucleus Accumbens
}

\author{
Mitra Heshmati, ${ }^{1}{ }^{\circledR}$ Daniel J. Christoffel, ${ }^{1}$ Katherine LeClair, ${ }^{1}$ Flurin Cathomas, ${ }^{1}{ }^{\circledR}$ Sam A. Golden, ${ }^{1}$ \\ ${ }^{\circ}$ Hossein Aleyasin, ${ }^{1}{ }^{\circledR}$ Gustavo Turecki, ${ }^{2}{ }^{-}$Allyson K. Friedman, ${ }^{1,3}$ Ming-Hu Han, ${ }^{1,3}{ }^{\circledR}$ Caroline Menard, \\ and ${ }^{\circledR}$ Scott J. Russo ${ }^{1}$ \\ ${ }^{1}$ Nash Family Department of Neuroscience, Friedman Brain Institute, Graduate School of Biomedical Sciences, Icahn School of Medicine at Mount \\ Sinai, New York, New York 10029, ${ }^{2}$ Douglas Research Centre, McGill University, Montreal, Quebec H4H 1R3, Canada, and ${ }^{3}$ Department of \\ Pharmacological Sciences, Icahn School of Medicine at Mount Sinai, New York, New York 10029
}

Chronic stress in both humans and rodents induces a robust downregulation of neuroligin-2, a key component of the inhibitory synapse, in the NAc that modifies behavioral coping mechanisms and stress resiliency in mice. Here we extend this observation by examining the role of two other inhibitory synapse constituents, vesicular GABA transporter (vGAT) and gephyrin, in the NAc of male mice that underwent chronic social defeat stress (CSDS) and in patients with major depressive disorder (MDD). We first performed transcriptional profiling of vGAT and gephyrin in postmortem NAc samples from a cohort of healthy controls, medicated, and nonmedicated MDD patients. In parallel, we conducted whole-cell electrophysiology recordings in the NAc of stress-susceptible and stress-resilient male mice following $10 \mathrm{~d}$ of CSDS. Finally, we used immunohistochemistry to analyze protein levels of vGAT and gephyrin in the NAc of mice after CSDS. We found that decreased vGAT and gephyrin mRNA in the NAc of nonmedicated MDD patients is paralleled by decreased inhibitory synapse markers and decreased frequency of mini inhibitory postsynaptic currents (mIPSC) in the NAc of susceptible mice, indicating a reduction in the number of NAc inhibitory synapses that is correlated with depression-like behavior. Overall, these findings suggest a common state of reduced inhibitory tone in the NAc in depression and stress susceptibility.

Key words: depression; inhibitory synapse; nucleus accumbens; social defeat; stress

Significance Statement

Existing studies focus on excitatory synaptic changes after social stress, although little is known about stress-induced inhibitory synaptic plasticity and its relevance for neuropsychiatric disease. These results extend our previous findings on the critical role of impaired inhibitory tone in the NAc following stress and provide new neuropathological evidence for reduced levels of inhibitory synaptic markers in human NAc from nonmedicated major depressive disorder patients. This finding is corroborated in stress-susceptible male mice that have undergone chronic social defeat stress, a mouse model of depression, at both the level of synaptic function and protein expression. These data support the hypothesis that reduced inhibitory synaptic transmission within the NAc plays a critical role in the stress response.

Received Oct. 28, 2019; revised Jan. 28, 2020; accepted Mar. 3, 2020.

Author contributions: M.H., D.J.C., A.K.F., C.M., and S.J.R. designed research; M.H., DJ.C., K.L., F.C., S.A.G., H.A., and C.M. performed research; M.H., D.J.C., F.C., S.A.G., G.T., A.K.F., M.-H.H., C.M., and S.J.R. analyzed data; M.H. and S.J.R. wrote the first draft of the paper; M.H., D.J.C., K.L., S.A.G., H.A., G.T., A.K.F., M.-H.H., C.M., and S.J.R. edited the paper; M.H., C.M., and S.J.R. wrote the paper; G.T. contributed unpublished reagents/analytic tools.

This work was supported by National Institutes of Health Grants R01 MH090264, R01 MH114882, R01 MH104559, P50 MH096890, and P50 AT008661 to S.J.R.; and National Institutes of Health Grants F30 MH100835, T32 MH087004, R56 MH115409, and R01 MH120637 to M.H.

M. Heshmati's present address: University of Washington, Center of Excellence in Neurobiology of Addiction Pain and Emotion, Seattle, Washington 98103.

S.A. Golden's present address: University of Washington, Center of Excellence in Neurobiology of Addiction Pain and Emotion, Seattle, Washington 98103.

C. Menard's present address: CERVO Brain Research Center, Université Laval, Quebec City, Quebec, Canada.

D.J. Christoffel's present address: Stanford University, Stanford, California 94305.

A.K. Friedman's present address: Hunter College, City University of New York, New York, New York 10065

The authors declare no competing financial interests.

Correspondence should be addressed to Scott J. Russo at scott.russo@mssm.edu.

https://doi.org/10.1523/JNEUROSCI.2568-19.2020

Copyright $\odot 2020$ the authors

\section{Introduction}

Stress disorders result in maladaptive plasticity within the brain's reward circuit that then mediates symptoms of anhedonia and social avoidance prevalent in depressed individuals. Preclinical models, such as chronic social defeat stress (CSDS), provide evidence that stress-induced synaptic plasticity within a number of different brain regions, including the NAc, PFC, and thalamus, among others, is causally linked to the expression of depressionlike behaviors. While prior studies focus predominantly on the remodeling of glutamatergic synapses (Christoffel et al., 2011, 2015; Golden et al., 2013; Dias et al., 2014; Veeraiah et al., 2014; Francis et al., 2015), recent evidence shows that CSDS-induced changes at inhibitory synapses in NAc promote stress susceptibility and the expression of depression-like behaviors (Heshmati et al., 2018). More specifically, we showed that CSDS reduces levels of the inhibitory synapse-specific protein, neuroligin 2, in 
NAc medium spiny neurons (MSNs) promoting social avoidance. Neuropathological evidence in humans confirmed reduced neuroligin-2 mRNA in NAc of unmedicated depressed subjects. Based on these data, we hypothesized that CSDS and depression may also promote changes to additional inhibitory synaptic markers as well as functional changes to inhibitory synapses in NAc.

We measured vesicular $\gamma$-aminobutyric acid transporter (vGAT) and gephyrin mRNA in postmortem human NAc and found reduced expression in nonmedicated depressed individuals. vGAT is shown to be a marker that reliably colocalizes to GABAergic presynaptic terminals, whereas gephyrin forms the postsynaptic scaffold of the inhibitory synapse (Chaudhry et al., 1998; Tyagarajan and Fritschy, 2014). Using whole-cell electrophysiology, we observed that stress-susceptible, but not resilient, male mice exhibit decreased NAc MSN mini inhibitory postsynaptic currents (mIPSC) frequency relative to controls, and that, conversely, resilient mice exhibit increased mIPSC amplitude relative to controls. mIPSC frequency, but not amplitude, was correlated with social avoidance behavior. Last, we confirmed that vGAT protein expression was decreased in susceptible mice, whereas gephyrin protein expression was increased in resilient mice. Overall, these findings extend previously published studies by providing new evidence for decreased inhibitory tone in NAc of stress-susceptible mice following CSDS and in MDD patients.

\section{Materials and Methods}

Experimental animals. Single-housed male CD-1 mice (4-month-old sexually experienced retired breeders) from Charles River Laboratories were used as aggressors in social defeat experiments. Eight-week-old C57BL6/J male mice from The Jackson Laboratory were used for slice electrophysiology and immunohistochemistry after exposure to CSDS. All mice were group-housed in a controlled environment (12 h light/ dark cycle) with food and water available ad libitum. Mice were singly housed 1 week before resident-intruder testing and $24 \mathrm{~h}$ before social interaction testing. Behavioral assessments and tissue collections were performed during the animals' light phase. All experiments were performed in accordance with the Icahn School of Medicine Institutional Animal Care and Use Committee.

CSDS. CSDS was performed as previously described (Berton et al., 2006; Krishnan et al., 2007). All CD-1 aggressors were screened for aggressive behavior before use according to published protocols (Golden et al., 2011). Experimental C57BL6/J mice encountered a novel CD-1 aggressor for $10 \mathrm{~min}$ daily over 10 consecutive days. Mice were housed opposite a perforated Plexiglas barrier between defeat sessions to enable continuous sensory contact with the aggressor. After $10 \mathrm{~d}$, experimental mice were singly housed overnight and underwent social interaction testing the following day.

Social interaction test. Social interaction testing was performed as previously described (Golden et al., 2011). Mice were placed over two $150 \mathrm{~s}$ trials into a novel, open-field arena with an interaction zone delineated. In the first "No target" trial, an empty cage was placed in the interaction zone. In the second "Target" trial, a novel CD-1 mouse was placed inside the cage in the interaction zone. Time spent in the interaction zone, distance traveled, and velocity were measured using Ethovision video tracking software (Noldus Technology). The social interaction ratio was calculated as time spent in the interaction zone in the "Target" trial divided by time spent in the interaction zone in the "No target" trial. Susceptible mice were defined by having a social interaction ratio $<1$ (Krishnan et al., 2007; Golden et al., 2011) .

Perfusion for immunohistochemistry. Following CSDS, mice were anesthetized with $15 \%$ chloral hydrate. Transcardial perfusion was performed with cold phosphate-buffered saline, $\mathrm{pH} 7.4$, followed by $4 \%$ PFA in PBS. Brains were dissected and postfixed overnight in $4 \%$ PFA.
Immunohistochemistry. Brains were perfused as described above, flash frozen after cryoprotection with sucrose, and $40 \mu \mathrm{m}$ slices containing the NAc were cut on a cryostat (CM1850, Leica Microsystems). The following primary antibody dilutions were used in blocking solution ( $3 \%$ normal donkey serum and $0.3 \%$ Triton $\mathrm{X}$ in PBS) with free-floating incubation overnight: 1:500 vGAT (guinea pig, Synaptic Systems, 131004) and 1:1000 gephyrin (rabbit, Abcam, ab32206). Slices were incubated in secondary fluorescent antibody (Donkey Cy2 or Cy3, Jackson ImmunoResearch Laboratories) for $2 \mathrm{~h}$. Images were acquired on an LSM 780 confocal microscope (Carl Zeiss) using a $100 \times$ oil immersion objective (pixel size of $0.17 \mu \mathrm{m}$ ). Images were deconvoluted with the AutoQuant software, and protein puncta were quantified using Image J 3D Object Counter.

Electrophysiology. All recordings were performed and analyzed blind to experimental condition, 3-20 d after social interaction testing, using methods based on previous studies in MSNs (Christoffel et al., 2011). Animals were perfused for $1 \mathrm{~min}$ with ice-cold aCSF containing the following (in mM): $128 \mathrm{NaCl}, 10 \mathrm{D}$-glucose, $1.25 \mathrm{NaH}_{2} \mathrm{PO}_{4}, 25 \mathrm{NaHCO}_{3}, 2$ $\mathrm{MgSO}_{4} \cdot 7 \mathrm{H}_{2} 0,3 \mathrm{KCl}, 2 \mathrm{CaCl}_{2} \cdot 2 \mathrm{H}_{2} \mathrm{O}, \mathrm{pH} 7.35$ (295-305 mOsm), carbogenated with $95 \% \mathrm{O}_{2} / 5 \% \mathrm{CO}_{2} ; 250 \mu \mathrm{m}$ acute brain slices containing the NAc were cut in sucrose-enriched aCSF containing $254 \mathrm{~mm}$ sucrose in place of $\mathrm{NaCl}$. Slices were incubated in the holding chamber for $1 \mathrm{~h}$ at $37^{\circ} \mathrm{C}$ before being transferred to a recording chamber with a constant flow rate $(2 \mathrm{ml} / \mathrm{min})$ of carbogenated aCSF at room temperature. MSNs in the NAc shell were identified by their size and location using infrared differential interference contrast microscopy and resting membrane potentials of -72 to $-80 \mathrm{mV}$ measured immediately on making patch access. mIPSC recordings were made in whole-cell voltage-clamp configuration using glass microelectrodes $(4-7 \mathrm{M} \Omega$ ) containing the following (in mM): $130 \mathrm{CsCl}, 10$ EGTA, 10 HEPES, 1 QX-314, $2 \mathrm{Mg}$-ATP, $0.2 \mathrm{Na}$ GTP, pH $7.2(285 \mathrm{mOsm})$ producing inward currents at a holding potential of $-80 \mathrm{mV}$. Miniature inhibitory currents were isolated by bath application of $1.5 \mu \mathrm{M}$ TTX (Tocris Bioscience), $10 \mu \mathrm{M}$ CNQX (Sigma Millipore), and $50 \mu \mathrm{M}$ APV (Sigma Millipore). Recordings were made with a computer-controlled amplifier (MultiClamp 700B), digitized (Digidata 1440), and acquired with Axoscope 10.1 (Molecular Devices) at a sampling rate of $10 \mathrm{kHz}$. Series resistance was monitored throughout the recordings, and $3 \mathrm{~min}$ of spontaneous activity per cell was analyzed using MiniAnalysis software (Synaptosoft). The same thresholds were used in the analysis of all cells. A total of $52(n=17$, $n=25, n=10)$ cells were analyzed from $(n=5, n=7, n=4)$ control, susceptible, and resilient animals, respectively.

Acquisition of postmortem human tissue. NAc tissue resections were collected at the local medical examiners' offices, after obtaining next-ofkin permission, by the Quebec Suicide Brain Bank at the Douglas Hospital Research Center under an approval of the Douglas Hospital Research Center's Research Ethics Committee. The NAc was dissected and immediately placed in a mixture of dry ice and isopentane (1:1 v:v) and stored at $-80^{\circ} \mathrm{C}$ until further processed for total RNA using TRIzol (Invitrogen) (for further description of qPCR, see below). Groups were matched for gender, age, $\mathrm{pH}$, postmortem interval (PMI), and RNA integrity number. Acceptable RNA integrity numbers ranged from 6.1 to 9.5 (Agilent Technologies, 2100 Bioanalyzer). Subjects were excluded if they had a known history of neurologic disease or head injury. For each subject, a review of clinical records, telephone interviews with primary caregivers, toxicology screen, and independent diagnosis by 3 or 4 mental healthcare professionals using the Diagnostic and Statistical Manual of Mental Disorders IV were confirmed. All depressed subjects died by suicide. Individual demographic characteristics are listed in Extended Data Table 1-1

$q P C R$. RNA isolation was performed using TRIzol (Invitrogen) homogenization and chloroform layer separation, followed by processing of the RNA layer (RNAeasy MicroKit, QIAGEN). RNA was analyzed with NanoDrop (Thermo Fisher Scientific) and reverse-transcribed to cDNA (qScript Kit, VWR). For qPCR, cDNA was diluted to $1 \mathrm{ng} / \mu \mathrm{l}$, and $3 \mu \mathrm{l}$ was used in each reaction. The reaction mixture consisted of $5 \mu \mathrm{l}$ Perfecta SYBR Green (VWR), $0.5 \mu \mathrm{l}$ each of forward and reverse primers, $1 \mu \mathrm{l}$ of water, and the cDNA template. Samples were heated to $95^{\circ}$ $\mathrm{C}$ for $2 \mathrm{~min}$ followed by 40 cycles of $95^{\circ} \mathrm{C}$ for $15 \mathrm{~s}, 60^{\circ} \mathrm{C}$ for $33 \mathrm{~s}$, and $72^{\circ}$ 
$\mathrm{C}$ for $33 \mathrm{~s}$. Analysis was performed using the $-\Delta \Delta \mathrm{C}_{\mathrm{T}}$ method, with sample normalization to GAPDH. IDT PrimeTime primers were purchased from Integrated DNA Technologies for both human and mouse vGAT and gephyrin genes.

Statistical analysis. All data are expressed as mean \pm SEM. Sample size estimates were based on previous experiments in social defeat stress (Heshmati et al., 2018). Mean differences between groups were determined using two-tailed Student's $t$ test, one-way ANOVA, or two-way ANOVA, followed by Bonferroni post-tests if the main effect was significant at $p<0.05$. Statistical analyses were performed using Prism 5.0 (GraphPad Software).
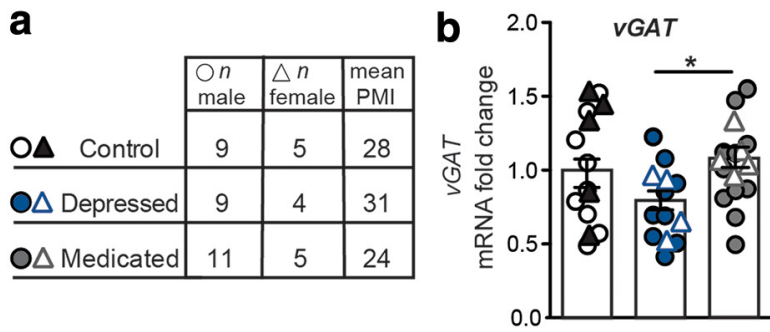

Figure 1. Expression of inhibitory synapse-related genes in postmortem NAc of patients with MDD. $\boldsymbol{a}$, Table summarizing number of male and female samples along with average PMI. Comprehensive demographics are listed in Extended Data Table 1-1. $\boldsymbol{b}$, MDD subjects exhibit significantly reduced mRNA fold change for vGAT between antidepressant-treated and untreated subjects (one-way ANOVA: $F_{(2,42)}=3.687,{ }^{*} p<0.05$ ). $c$, Untreated MDD subjects exhibit significantly lower gephyrin mRNA fold change, whereas treated subjects exhibit significantly higher gephyrin compared with untreated subjects (one-way ANOVA: $F_{(2,42)}=7.030,{ }^{* *} p<0.01$ ), ${ }^{*} p<0.01$. ${ }^{* *} p<0.001$. Data are mean \pm SEM. For human subject demographics, see Extended Data Table 1-1.

\section{Results}

In order to assay changes to NAc inhibi-

tory synapse markers in MDD, we used qPCR profiling of both presynaptic and postsynaptic inhibitory synapse markers in postmortem samples from healthy controls versus patients with MDD as described previously (Chaudhry et al., 1998; Dobie and Craig, 2011). We find that mRNA levels of vGAT, an inhibitory presynaptic marker, are decreased in the nonmedicated depressed subjects compared with those on antidepressant medication at the time of death, suggesting that standard antidepressant medications have some efficacy in normalizing inhibitory synaptic plasticity-related gene expression (Fig. 1a; one-way ANOVA: $\left.F_{(2,42)}=3.687, p<0.05\right)$. Similarly, mRNA levels of the postsynaptic inhibitory marker gephyrin are significantly decreased in the nonmedicated MDD group and increased in the medicated MDD group, with the medicated group showing similar levels as healthy controls (Fig. $1 b$; one-way ANOVA: $F_{(2,42)}=$ $7.030, p<0.01)$. Analyses using sex as a variable demonstrate no significant difference between male and female samples for vGAT (two-way ANOVA: $F_{(2,37)}=0.29, p>0.05$ ) or gephyrin (two-way ANOVA: $F_{(2,37)}=0.70, p>0.05$ ). Overall, these data suggest a downregulation of inhibitory synapses in MDD that is restored with antidepressant medication.

We next used CSDS in mice to further investigate functional changes in inhibitory synapses (Fig. 2). Following $10 \mathrm{~d}$ of CSDS, the social interaction test was performed to determine susceptibility to stress using time spent in the interaction zone with a novel animal present (Fig. $2 b$; two-way ANOVA: $F_{(2,26)}=7.99$, $p<0.01$ ), as well as the social interaction ratio, determined by the ratio of time spent in the interaction zone with a target animal present divided by time spent in the interaction zone with the target animal absent (Fig. $2 c$; one-way ANOVA: $F_{(2,15)}=$ $20.28, p<0.001)$. Notably, there is no difference in baseline locomotor activity between groups, measured as distance traveled in the target absent trial (Fig. 2d; one-way ANOVA, $p>0.05$ ). Next, whole-cell recording of mIPSCs was performed in NAc shell MSNs from susceptible, control, and resilient mice to investigate functional changes to inhibitory synapses (Fig. $3 a$, representative traces). We find that susceptible mice display a significant decrease in MIPSC frequency (Fig. $3 b$; one-way ANOVA: $\left.F_{(2,51)}=8.254, p<0.0008\right)$, whereas resilient mice show an increase in MIPSC amplitude compared with controls (Fig. $3 c$; one-way ANOVA: $F_{(2,53)}=4.801, p<0.012$ ). The change in mIPSC frequency significantly correlates with social interaction ratio (Fig. $3 d ; r^{2}=0.27, p<0.05$ ), supporting a decrease in the number of NAc inhibitory synapses associated with increased social avoidance behavior. Conversely, the increase in mIPSC amplitude in resilient animals does not significantly correlate with social interaction ratio (Fig. $3 e ; p>0.05$ ).

In order to further examine changes to the number of inhibitory synapses after stress, immunohistochemistry for vGAT and gephyrin was performed in a separate cohort of mice after CSDS (Fig. $4 a$; representative images). vGAT puncta are significantly reduced in the NAc of mice susceptible to stress, paralleling the reduction in MIPSC frequency and further supporting a reduction in the overall number of inhibitory synapses after stress (Fig. $4 b$; one-way ANOVA: $\left.F_{(2,21)}=4.45, p<0.05\right)$. The reduction in vGAT puncta correlates significantly with decreased social interaction ratio (Fig. $4 d ; r^{2}=0.53, p=0.0001$ ). Interestingly, the number of postsynaptic gephyrin puncta is increased in the resilient population, coinciding with the increased mIPSC amplitude observed in recordings from resilient mice (Fig. $4 c$; one-way ANOVA: $\left.F_{(2,21)}=4.26, p<0.05\right)$. The change in gephyrin also correlates with increased social interaction ratio (Fig. $4 e ; r^{2}=$ $0.25, p=0.018)$. There is a trend, but not a significant decrease, in gephyrin puncta in susceptible animals. This suggests that the change in MIPSC frequency in susceptible mice may be driven by a loss of inhibitory presynaptic inputs into the NAc, while resiliency is characterized by a strengthening of NAc inhibitory tone.

To evaluate the region specificity of these inhibitory synapse changes, vGAT and gephyrin mRNA levels are assayed in the dorsal striatum of mice following CSDS. There is a significant stress-induced increase in vGAT mRNA levels in the dorsal striatum of both susceptible and resilient mice (Fig. $5 a$; one-way ANOVA: $\left.F_{(2,21)}=11.75, p<0.05\right)$. There is no change in gephyrin mRNA levels in the dorsal striatum after CSDS (Fig. $5 b ; p>0.05)$. Overall, these data support the specificity of our findings in the ventral striatum, specifically assayed in NAc shell of mouse samples and combined NAc shell and core in human samples. Together, these data support a downregulation of NAc inhibitory tone in CSDS and MDD that is restored by antidepressant treatment and increased in stress resiliency.

\section{Discussion}

Synaptic plasticity in the mesolimbic dopamine system is an important component of the stress response that may underlie subsequent development of psychiatric disorders (Russo and Nestler, 2013; Fox and Lobo, 2019). Evidence supports changes in NAc excitatory synapses following CSDS in mice, with prior studies demonstrating increased mEPSCs and increased number of dendritic spine excitatory synapses in the NAc of mice that are 
a

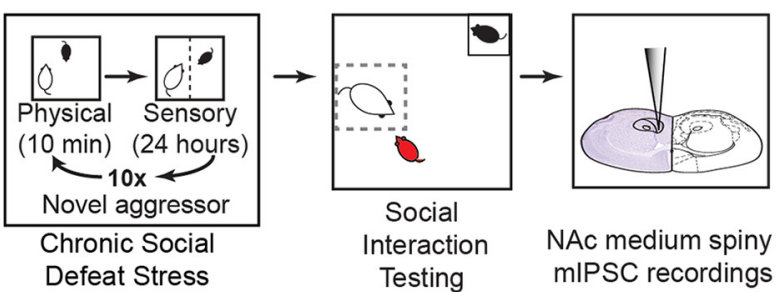

b
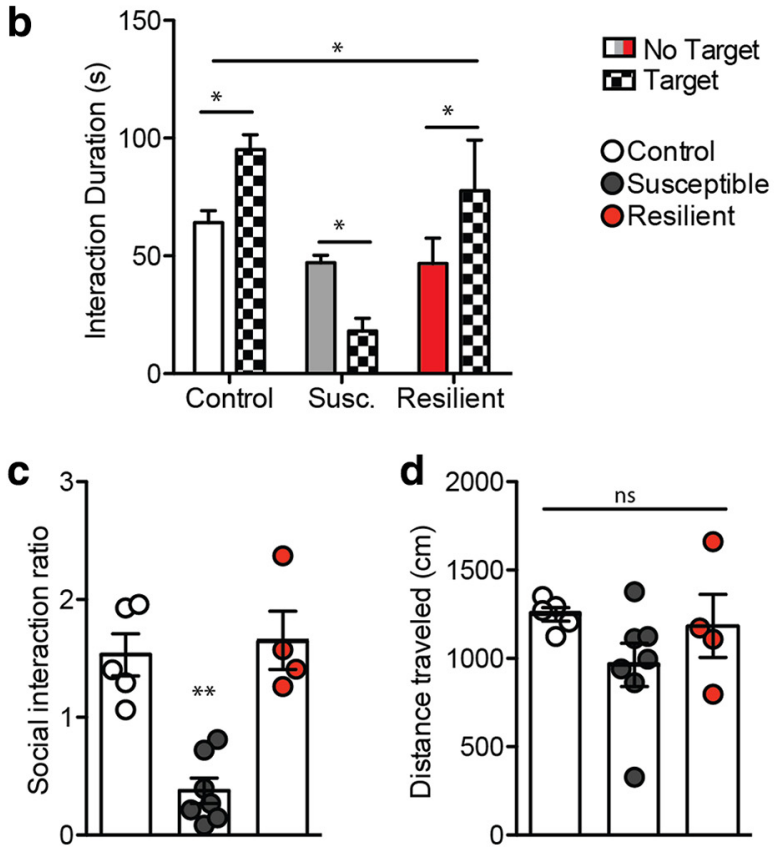

Figure 2. Effects of CSDS on mIPSCS in NAc MSNs. $\boldsymbol{a}$, Experimental timeline. $\boldsymbol{b}$, Susceptible mice spend less time in the interaction zone during the novel target animal trial, whereas control and resilient mice spend more time in the interaction zone with a target present (two-way ANOVA: $\left.F_{(2,26)}=7.99,{ }^{* *} p<0.01\right)$. c, The ratio of time spent in the interaction zone with a target present divided by time spent in the interaction zone with target absent produces a social interaction ratio that is reduced in mice defined as susceptible to stress compared with control and resilient mice (one-way ANOVA: $\left.F_{(2,15)}=20.28\right)$. $\boldsymbol{d}$, There is no significant effect of locomotor activity between groups as shown by distance traveled during the no target trial (one-way ANOVA, $p>0.05$ ). ${ }^{*} p<0.01,{ }^{* *} p<0.001$. Data are mean \pm SEM. ns, not significant.

susceptible, but not resilient, to stress (Christoffel et al., 2011). From a functional perspective, increased excitatory tone, predominantly on dopamine D2 receptor-containing MSNs, drives behavioral susceptibility to stress (Francis et al., 2015). While changes in excitatory synapses within NAc are well characterized, few studies investigate a role for inhibitory synaptic plasticity in NAc after chronic stress and depression.

Our results confirm that social defeat stress also results in a loss of inhibitory synaptic function in susceptible mice. These changes in inhibitory function are likely due to both a loss of presynaptic inhibitory inputs given that we observe reduced vGAT puncta and mIPSC frequency in susceptible mice as well as changes to inhibitory postsynaptic compartments, given that we see upregulation of gephyrin puncta and MIPSC amplitude in resilient mice. Alterations to mIPSC frequency are a reflection of changes to inhibitory presynaptic inputs, correlated with decreased vGAT expression (Chaudhry et al., 1998; Lalchandani et al., 2013). Alterations in mIPSC amplitude likely reflect changes to the postsynaptic inhibitory synapse, measured by gephyrin expression (Tyagarajan and Fritschy, 2014; Pizzarelli et al., 2020). Importantly, these findings are corroborated in human a

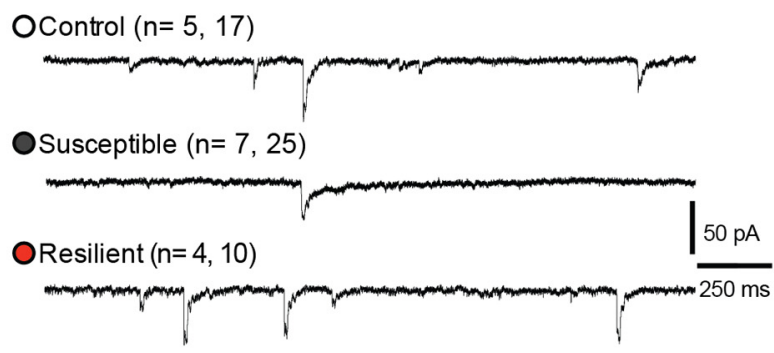

b
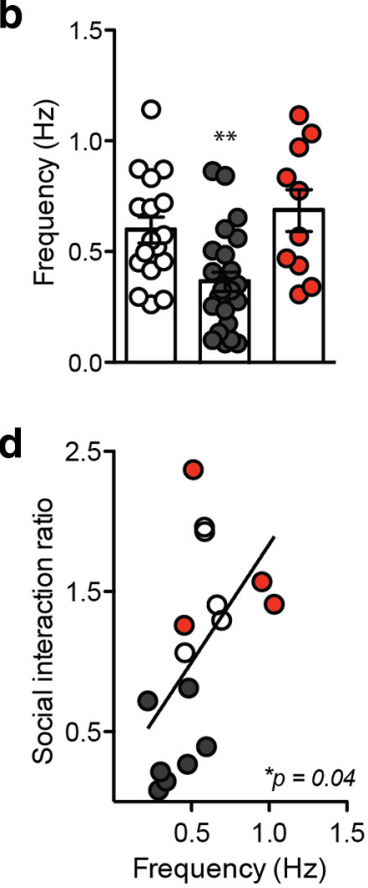

C
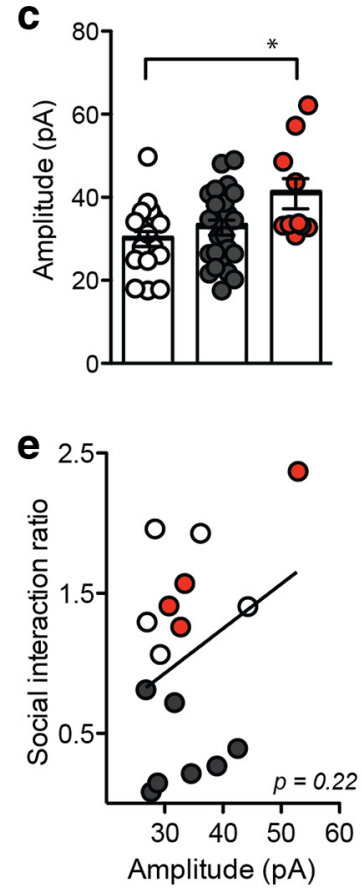

Figure 3. Changes in mIPSCs correlate with behavioral phenotype after CSDS. $\boldsymbol{a}$, Representative traces from whole-cell voltage-clamp recordings of mIPSCs from NAC MSNs after CSDS. Calibration: $250 \mathrm{~ms}, 50 \mathrm{pA}$. $\boldsymbol{b}$, MSNs from susceptible mice display significantly reduced mIPSC frequency (one-way ANOVA: $\left.F_{(2,51)}=8.254\right)$. c, NAc MSNs from resilient mice show significantly increased mIPSC amplitude (one-way ANOVA: $F_{(2,53)}=4.801,{ }^{*} p<0.012$; $n=17$ control, 25 susceptible, 10 resilient cells recorded from 5 control, 7 susceptible, 4 resilient mice). $\boldsymbol{d}$, Decreased mIPS( frequency significantly correlates with lower social interaction ratio $\left(r^{2}=0.27,{ }^{*} p<0.05\right)$. $\boldsymbol{e}$, Changes in mIPSC amplitude in resilient mice do not significantly correlate with social interaction ratio $(p>0.05) .{ }^{*} p<0.01,{ }^{* *} p<0.001$. Data are mean \pm SEM

postmortem NAc from MDD subjects, highlighting the translational value of our findings. Multiple sources of inhibitory inputs within NAc may contribute to these inhibitory synapse changes, including GABAergic projections from VTA, local NAc GABAergic interneurons, and MSN inhibitory collateral networks (Kawaguchi et al., 1995; Taverna et al., 2008; Gittis et al., 2010; van Zessen et al., 2012). Together, our work supports a model of increased excitatory tone and decreased inhibitory tone promoting susceptibility to stress and depression (Fig. 6).

Despite inherent limitations of stress models in rodents, preclinical studies are integral to furthering understanding of the neurobiological changes underlying mood and anxiety disorders. CSDS is an animal model with both face and predictive validity. Analogous to a human population subjected to daily life stress, not all mice subjected to CSDS are susceptible to stress. Depression-like behaviors induced by CSDS are uniquely reversed by chronic, not acute, administration of antidepressant medication, similar to human MDD patients. Thus, the CSDS model enables an exploration of the biological mechanisms 

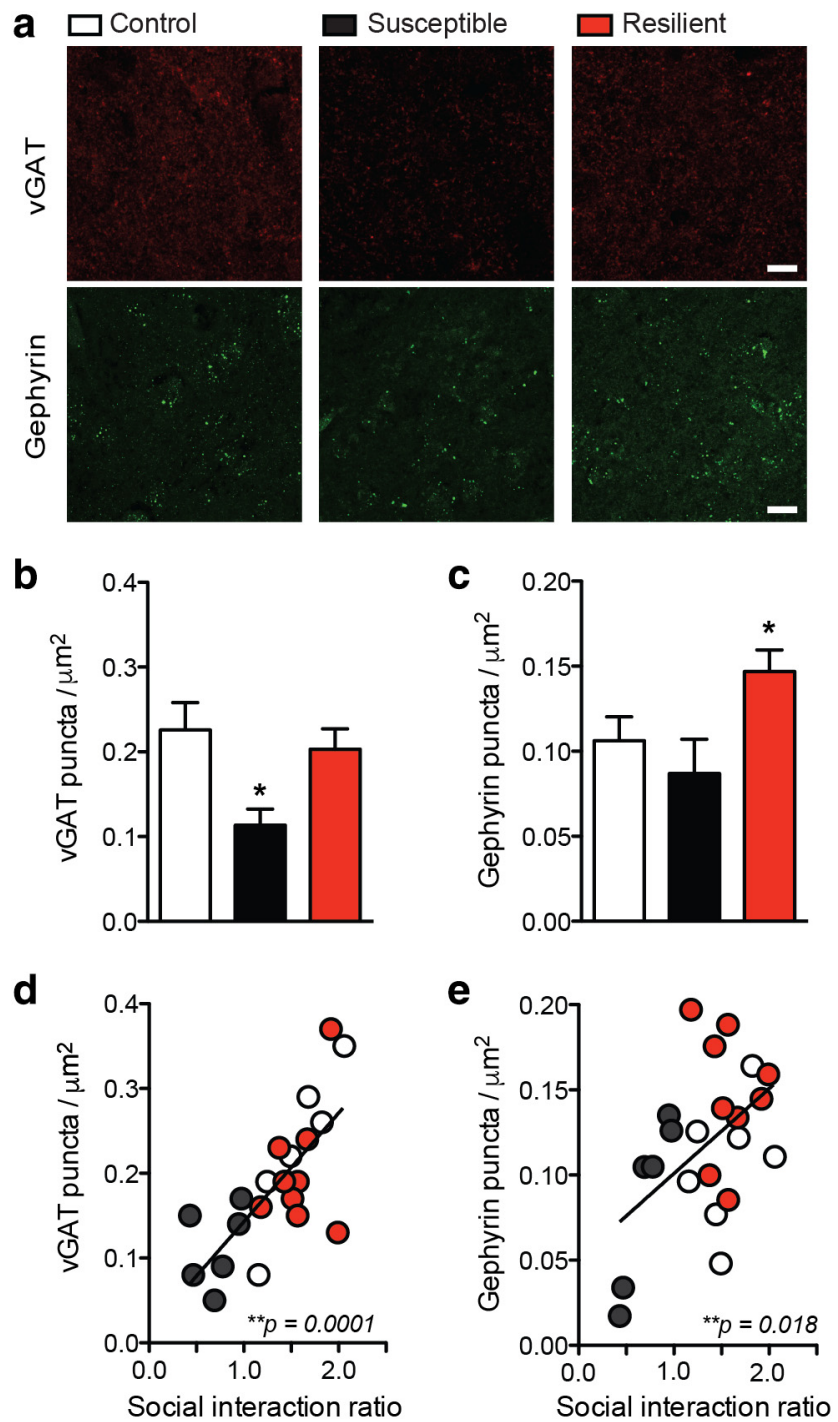

Figure 4. Inhibitory synaptic protein levels correlate with social stress susceptibility versus resilience after CSDS. $\boldsymbol{a}$, Representative images of vGAT and gephyrin immunohistochemistry in the NAc of control, susceptible, and resilient mice after CSDS. Scale bar, $20 \mu \mathrm{m} . \boldsymbol{b}, \mathrm{vGAT}$ puncta are reduced in susceptible mice (one-way ANOVA: $F_{(2,21)}=4.45,{ }^{*} p<0.05$ ). c, Gephyrin puncta are increased in resilient mice (one-way ANOVA: $F_{(2,21)}=4.26,{ }^{*} p<0.05$ ). $\boldsymbol{d}$, vGAT level correlates with social interaction ratio $\left(r^{2}=0.53\right)$. $\boldsymbol{e}$, Gephyrin level correlates with social interaction ratio $\left(r^{2}=0.25,{ }^{* *} p=0.018\right)$. Detailed CSDS behavioral data for the animals used in the immunohistochemistry study published previously (Heshmati et al., 2018). ${ }^{*} p<0.01$. Data are mean \pm SEM.
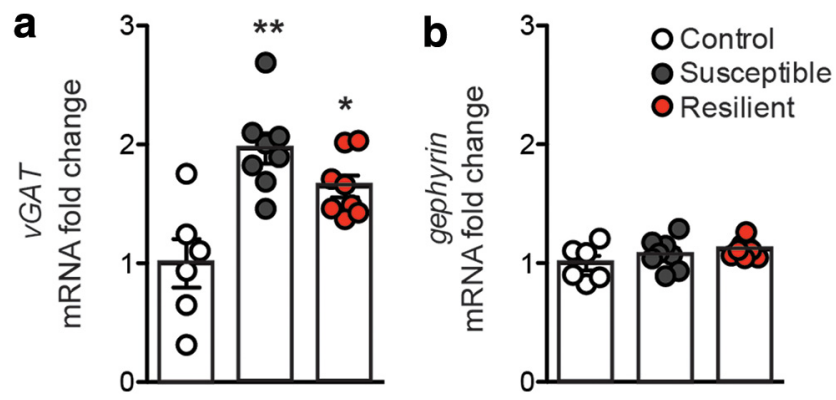

Figure 5. Inhibitory synapse gene changes in the dorsal striatum after CSDS. $\boldsymbol{a}$, vGAT mRNA is significantly upregulated in the dorsal striatum of both susceptible and resilient mice (one-way ANOVA: $F_{(2,21)}=11.75,{ }^{*} p<0.05$ and $\left.{ }^{* *} p<0.005\right)$. $\boldsymbol{b}$, There is no change in gephyrin mRNA levels in dorsal striatum after CSDS. Data are mean \pm SEM.

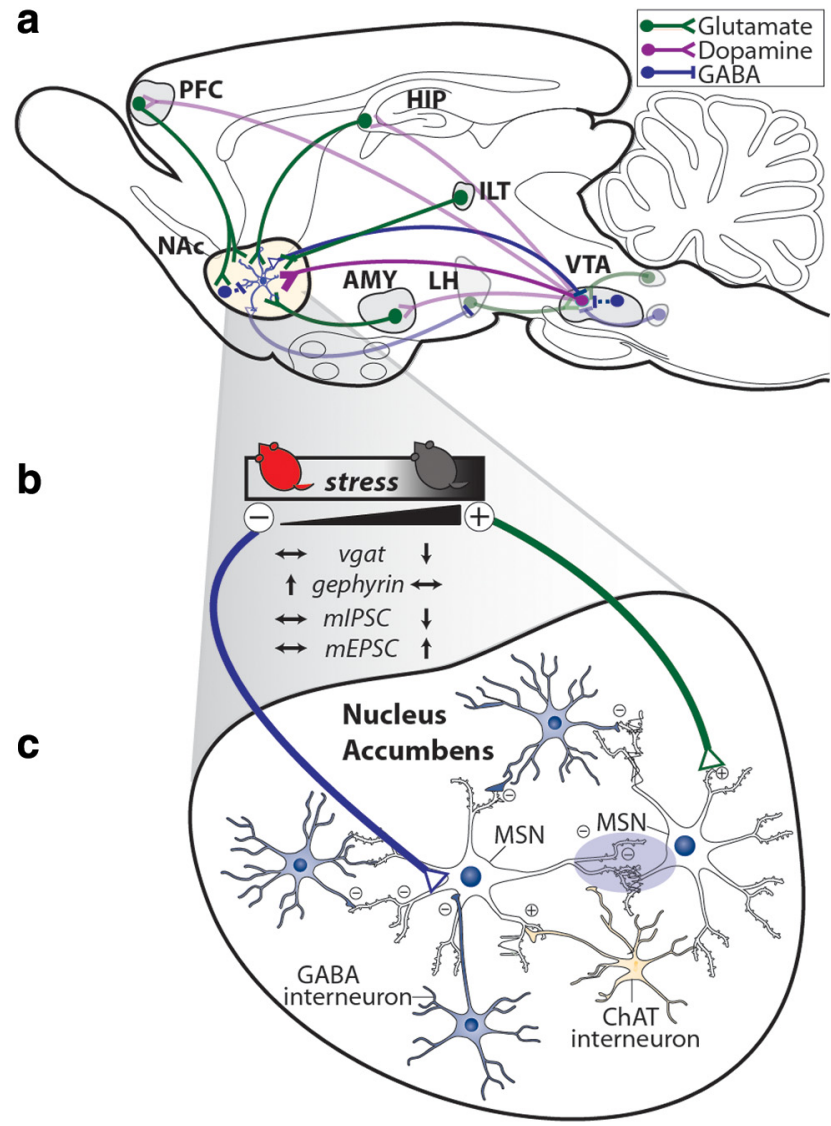

Figure 6. Model of inhibitory and excitatory synaptic changes in the NAc after CSDS. $\boldsymbol{a}$, Overview of mesolimbic dopamine circuitry in the mouse brain with glutamatergic (green), dopaminergic (purple), and GABAergic (blue) projections to NAc shown from primary input regions. VTA neurons may release glutamate in addition to dopamine. $\boldsymbol{b}$, Summary of changes to synaptic plasticity in NAc with increasing susceptibility to stress. c, Stress promotes shifts in NAc excitatory and inhibitory tone with susceptible mice characterized by an overall increase in glutamatergic synapses and a decrease in GABAergic synapses. In addition to receiving inhibitory inputs from different populations of NAc interneurons, MSNs synapse on each other to form an intricate inhibitory microcircuit within NAC.

underlying susceptibility to stress in comparison with those that confer resilience to stress, as well as antidepressant responses. In addition, to enhance translational relevance, it is critical to validate findings from preclinical stress models using postmortem samples. Thus, our parallel findings of changes to inhibitory synaptic function in both susceptible mice following CSDS and human MDD together support the possibility that inhibitory function in the NAc may be a therapeutic target for depression treatment.

One important limitation of the CSDS model is that these studies are restricted to male animals due to the requirement for aggressive resident-intruder interactions. Future studies should investigate changes to NAc inhibitory synaptic plasticity in additional chronic stress procedures, such as chronic variable stress or newly established repeated social stress models that have enabled inclusion of female mice (Hodes et al., 2015; Takahashi et al., 2017; Harris et al., 2018; Newman et al., 2019; Yohn et al., 2019). Of note, using an established chronic mild stress protocol, we recently showed that depression-like behavior is associated with increased frequency of PSD-95 puncta, which is a marker of postsynaptic excitatory synapses (Brancato et al., 2017; Zhang et al., 2018).

In conclusion, we identified changes in inhibitory synaptic plasticity in an established model for the study of depression in 
rodents that are corroborated in postmortem NAc from depressed human subjects. Together with published data showing that increased excitatory drive is associated with stress susceptibility, the current results support a promising role for targeting inhibitory systems within the NAc to restore synaptic balance to promote stress resiliency.

\section{References}

Berton O, McClung CA, Dileone RJ, Krishnan V, Renthal W, Russo SJ, Graham D, Tsankova NM, Bolanos CA, Rios M, Monteggia LM, Self DW, Nestler EJ (2006) Essential role of BDNF in the mesolimbic dopamine pathway in social defeat stress. Science 311:864-868.

Brancato A, Bregman D, Ahn HF, Pfau ML, Menard C, Cannizzaro C, Russo SJ, Hodes GE (2017) Sub-chronic variable stress induces sex-specific effects on glutamatergic synapses in the nucleus accumbens. Neuroscience 350:180-189.

Chaudhry FA, Reimer RJ, Bellocchio EE, Danbolt NC, Osen KK, Edwards RH, Storm-Mathisen J (1998) The vesicular GABA transporter, VGAT, localizes to synaptic vesicles in sets of glycinergic as well as GABAergic neurons. J Neurosci 18:9733-9750.

Christoffel DJ, Golden SA, Walsh JJ, Guise KG, Heshmati M, Friedman AK, Dey A, Smith M, Rebusi N, Pfau M, Ables JL, Aleyasin H, Khibnik LA, Hodes GE, Ben-Dor GA, Deisseroth K, Shapiro ML, Malenka RC, Ibanez-Tallon I, Han MH, et al. (2015) Excitatory transmission at thalamo-striatal synapses mediates susceptibility to social stress. Nat Neurosci 18:962-964.

Christoffel DJ, Golden SA, Dumitriu D, Robison AJ, Janssen WG, Ahn HF, Krishnan V, Reyes CM, Han MH, Ables JL, Eisch AJ, Dietz DM, Ferguson D, Neve RL, Greengard P, Kim Y, Morrison JH, Russo SJ (2011) IkappaB kinase regulates social defeat stress-induced synaptic and behavioral plasticity. J Neurosci 31:314-321.

Dias C, Feng J, Sun H, Shao NY, Mazei-Robison MS, Damez-Werno D, Scobie K, Bagot R, LaBonté B, Ribeiro E, Liu X, Kennedy P, Vialou V, Ferguson D, Peña C, Calipari ES, Koo JW, Mouzon E, Ghose S, Tamminga C, et al. (2014) Beta-catenin mediates stress resilience through Dicer1/microRNA regulation. Nature 516:51-55.

Dobie FA, Craig AM (2011) Inhibitory synapse dynamics: coordinated presynaptic and postsynaptic mobility and the major contribution of recycled vesicles to new synapse formation. J Neurosci 31:10481-10493.

Fox ME, Lobo MK (2019) The molecular and cellular mechanisms of depression: a focus on reward circuitry. Mol Psychiatry 24:1798-1815.

Francis TC, Chandra R, Friend DM, Finkel E, Dayrit G, Miranda J, Brooks JM, Iñiguez SD, O’Donnell P, Kravitz A, Lobo MK (2015) Nucleus accumbens medium spiny neuron subtypes mediate depression-related outcomes to social defeat stress. Biol Psychiatry 77:212-222.

Gittis AH, Nelson AB, Thwin MT, Palop JJ, Kreitzer AC (2010) Distinct roles of GABAergic interneurons in the regulation of striatal output pathways. J Neurosci 30:2223-2234.

Golden SA, Christoffel DJ, Heshmati M, Hodes GE, Magida J, Davis K, Cahill ME, Dias C, Ribeiro E, Ables JL, Kennedy PJ, Robison AJ, Gonzalez-Maeso J, Neve RL, Turecki G, Ghose S, Tamminga CA, Russo SJ (2013) Epigenetic regulation of RAC1 induces synaptic remodeling in stress disorders and depression. Nat Med 19:337-344.

Golden SA, Covington HE, Berton O, Russo SJ (2011) A standardized protocol for repeated social defeat stress in mice. Nat Protoc 6:1183-1191.
Harris AZ, Atsak P, Bretton ZH, Holt ES, Alam R, Morton MP, Abbas AI, Leonardo ED, Bolkan SS, Hen R, Gordon JA (2018) A novel method for chronic social defeat stress in female mice. Neuropsychopharmacology 43:1276-1283.

Heshmati M, Aleyasin H, Menard C, Christoffel DJ, Flanigan ME, Pfau ML, Hodes GE, Lepack AE, Bicks LK, Takahashi A, Chandra R, Turecki G, Lobo MK, Maze I, Golden SA, Russo SJ (2018) Cell-type-specific role for nucleus accumbens neuroligin-2 in depression and stress susceptibility. Proc Natl Acad Sci USA 115:1111-1116.

Hodes GE, Pfau ML, Purushothaman I, Ahn HF, Golden SA, Christoffel DJ, Magida J, Brancato A, Takahashi A, Flanigan ME, Ménard C, Aleyasin H, Koo JW, Lorsch ZS, Feng J, Heshmati M, Wang M, Turecki G, Neve R, Zhang B, et al. (2015) Sex differences in nucleus accumbens transcriptome profiles associated with susceptibility versus resilience to subchronic variable stress. J Neurosci 35:16362-16376.

Kawaguchi Y, Wilson CJ, Augood SJ, Emson PC (1995) Striatal interneurones: chemical, physiological and morphological characterization. Trends Neurosci 18:527-535.

Krishnan V, Han MH, Graham DL, Berton O, Renthal W, Russo SJ, Laplant Q, Graham A, Lutter M, Lagace DC, Ghose S, Reister R, Tannous P, Green TA, Neve RL, Chakravarty S, Kumar A, Eisch AJ, Self DW, Lee FS, et al. (2007) Molecular adaptations underlying susceptibility and resistance to social defeat in brain reward regions. Cell 131:391-404.

Lalchandani RR, van der Goes MS, Partridge JG, Vicini S (2013) Dopamine D2 receptors regulate collateral inhibition between striatal medium spiny neurons. J Neurosci 33:14075-14086.

Newman EL, Covington HE, Suh J, Bicakci MB, Ressler KJ, DeBold JF, Miczek KA (2019) Fighting females: neural and behavioral consequences of social defeat stress in female mice. Biol Psychiatry 86:657-668.

Pizzarelli R, Griguoli M, Zacchi P, Petrini EM, Barberis A, Cattaneo A, Cherubini E (2020) Tuning GABAergic inhibition: gephyrin molecular organization and functions. Neuroscience 439:125-136.

Russo SJ, Nestler EJ (2013) The brain reward circuitry in mood disorders. Nat Rev Neurosci 14:609-625.

Takahashi A, Chung JR, Zhang S, Zhang H, Grossman Y, Aleyasin H, Flanigan ME, Pfau ML, Menard C, Dumitriu D, Hodes GE, McEwen BS, Nestler EJ, Han MH, Russo SJ (2017) Establishment of a repeated social defeat stress model in female mice. Sci Rep 7:12838.

Taverna S, Ilijic E, Surmeier DJ (2008) Recurrent collateral connections of striatal medium spiny neurons are disrupted in models of Parkinson's disease. J Neurosci 28:5504-5512.

Tyagarajan SK, Fritschy JM (2014) Gephyrin: a master regulator of neuronal function? Nat Rev Neurosci 15:141-156.

van Zessen R, Phillips JL, Budygin EA, Stuber GD (2012) Activation of VTA GABA neurons disrupts reward consumption. Neuron 73:1184-1194.

Veeraiah P, Noronha JM, Maitra S, Bagga P, Khandelwal N, Chakravarty S, Kumar A, Patel AB (2014) Dysfunctional glutamatergic and $\gamma$-aminobutyric acidergic activities in prefrontal cortex of mice in social defeat model of depression. Biol Psychiatry 76:231-238.

Yohn CN, Dieterich A, Bazer AS, Maita I, Giedraitis M, Samuels BA (2019) Chronic non-discriminatory social defeat is an effective chronic stress paradigm for both male and female mice. Neuropsychopharmacology 44:2220-2229.

Zhang S, Zhang H, Ku SM, Juarez B, Morel C, Tzavaras N, Montgomery S, Hodes GE, Brancato A, Russo SJ, Cao JL, Han MH (2018) Sex differences in the neuroadaptations of reward-related circuits in response to subchronic variable stress. Neuroscience 376:108-116. 